\title{
Strategi Public Relations PT Indotama Karya Gemilang Dalam Meningkatkan Pemahaman Proses Prosedural Tenaga Kerja Indonesia
}

\author{
Mareta Puri Rahastine ${ }^{1}$, Silvina Mayasari ${ }^{2}$, Natasha Sasmita ${ }^{3}$ \\ ${ }^{1}$ Universitas Bina Sarana Informatika/Fakultas Komunikasi Dan Bahasa \\ mareta.mpr@bsi.ac.id \\ ${ }^{2}$ Universitas Bina Sarana Informatika/Fakultas Komunikasi Dan Bahasa \\ silvina.svm@bsi.ac.id \\ ${ }^{3}$ Universitas Bina Sarana Informatika/Fakultas Komunikasi Dan Bahasa \\ anastashasmita@gmail.com
}

Cara Sitasi: Rahastine, M.P., Mayasari, S., Sasmita, N. (2019). Strategi Public Relations PT Indotama Karya Gemilang Dalam Meningkatkan Pemahaman Proses Prosedural Tenaga Kerja Indonesia. Cakrawala, 19(2), 237 242. Retrieved from doi: https://doi.org/10.31294/jc.v19i2

\begin{abstract}
Indonesian Workers (TKI) are domestic workers who work abroad. TKI is the largest foreign exchange earner for Indonesia. For official migrant workers, they will receive employment training conducted at the Overseas Employment Training Center which is managed by Indonesian Manpower Services Distributors as their suppliers abroad. Since the height of the news about Human Trafficking / non-procedural human trafficking has become a special concern by the Indonesian government, various ways of prevention are carried out by the government together with related official institutions. The author uses descriptive-qualitative research method, which is done by direct observation and in-depth interviews with the parties concerned, and the data collected later on analysis by descriptive analysis by describing the results of research in the form of research reports. With the holding of campaigns by the government and related institutions such as that carried out by PT Indotama Karya Gemilang about understanding the importance of the procedural process for migrant workers, they can add their understanding of the process procedurally.
\end{abstract}

Key Word: Strategy, Public Relations, Indonesian Workers

\section{PENDAHULUAN}

Tenaga Kerja Indonesia atau yang sering kita dengar dengan sebutan TKI adalah tenaga kerja dalam negeri yang bekerja di luar negeri. TKI merupakan salah satu penghasil devisa terbesar untuk Indonesia.

Jika dilihat dari tahun ke tahun jumlah minat masyarakat Indonesia untuk bekerja di luar negeri meningkat setiap tahunnya. Berdasarkan data yang dihimpun oleh World Bank, ada sekitar 9 juta penduduk Indonesia yang telah bekerja di luar negeri. (Putera, 2018)

Bank Indonesia telah mencatat total remintasi Tenaga Kerja Indonesia pada tahun 2015 mencapai hingga 119 triliun rupiah. Adapun, pada 2016 hingga oktober jumlahnya mencapai 97,5 triliun rupiah. Kepastian jumlah totalnya dilaporkan pada febuari 2016. (Sitorus, 2017)

Berbagai faktor yang menyebabkan rakyat Indonesia memilih untuk bekerja di luar negeri, diantarnya ingin mendapatkan penghasilan lebih, ingin mencari pengalaman kerja, kurangnya lapangan kerja di wilayah tertentu (Indonesia) dan masih banyak lagi.

Sayangnya tidak semua masyarakat Indonesia yang ingin bekerja ke luar negeri memahami tentang prosedur- prosedur yang berlaku, banyak dari mereka yang memilih jalan pintas untuk dapat bekerja ke luar negeri. Hal ini yang menjadi permasalahan terpenting yang perlu diatasi oleh pemerintah dan instansi- instansi terkait, bagaimana dapat memberikan pengetahunnya tentang pentingnya proses procedural.

Menurut data Kementrian Sosial RI, sebanyak 56 ribu tenaga kerja Indonesia sudah dipulangkan dari Malaysia. Berdasarkan data Kemensos, jumlah TKI bermasalah itu dihitung sejak 2015 sampai Juli 2018. Sementara itu, Direktur Rehabilitasi Sosial Tuna Sosial dan Korban Perdagangan Orang. Kementerian Sosial Sonny W Manalu mengatakan, selain mengalami masalah mental sehubungan dengan lingkungan sosial, TKI dideportasi karena terkena masalah hukum dan mayoritas karena tak punya dokumen lengkap.

Dari latar belakang masalah di atas, penulis yang menamakan diri sebagai ABHINAYA bekerjasama dengan PT Indotama Karya Gemilang untuk menyelanggarakan kampanye public relations dengan tema "Strategi Public Relations PT Indotama Karya Gemilang Dalam Meningkatkan Pemahaman Proses Prosedural Tenaga Kerja Indonesia", penulis berharap dengan diadakan nya kampanye public relations ini akan ada respon yang positif antara kedua belah pihak yang sama- sama peduli akan pentingnya proses prosedural bagi masyarakat Indonesia. 
Dalam penelitian ini penulis menguraikan beberapa konsep yang terkait dengan penelitian, sebagai berikut:

Menurut Dr. Rex Harlow dalam (Inoue, 2018)Public Relations (PR) adalah fungsi manajemen yang khas dan mendukung pembinaan, pemeliharaan jalur bersama antara organisasi dengan publiknya, menyangkut aktivitas komunikasi, pengertian, penerimaan dan kerja sama; melibatkan manajemen dalam menghadapi persoalan/permasalahan, membantu manajemen dalam mengikuti dan memenfaatkan perubahan secara efektif; bertindak sebagai sistem peringatan dini dalam mengantisipasi kecenderungan penggunaan penelitian serta teknik komunikasi yang sehat dan etis sebagai sarana utama

\section{Jenis Kampanye}

Menurut Larson dalam (USMAN, 2015) membagi jenis kampanye dalam tiga kategori, yakni: product-oriented campaigns, candidate-orianted campaigns, dan ideology or cause oriented campaigns.Product-oriented campaigns atau kampanye yang berorientasi pada produk, Candidateorianted campaigns atau kampanye yang berorientasi pada kandidat dan Ideology or cause oriented campaigns adalah jenis kampanye yang beriorentasi pada tujuan-tujuan yang bersifat khusus dan seringkali berdimensi perubahan sosial.

\section{Media}

Kata media berasal dari bahasa latin medius yang secara harfiah berarti 'tengah', 'perantara' atau 'pengantar'. Dalam bahasa Arab, media adalah perantara atau pengantar pesan dari pengirim kepada penerima pesan(Satrianawati, 2018).

Jenis-jenis Media

Menurut Djamarah dalam (Mokhammad, 2018) media dibagi menjadi 3 jenis, yakni :

1. Media auditif, yaitu media yang mengandalkan kemampuan suara saja (radio, kaset rekorder).

2. Media Visual, yaitu media yang hanya mengandalkan indera penglihatan karena hanya menampilkan gambar diam (film, bingkai, foto, gambar, atau lukisan).

3. Media Audiovisual, yaitu media yang mempunyai unsur suara dan unsur gambar. Jenis media ini mempunyai kemampuan yang lebih baik.

\section{Prosedur}

Ismail Masya berpendapat bahwa prosedur merupakan suatu rangkaian tugas-tugas yang saling terkait dan diatur dengan urutan dan tata cara tertentu, yang sengaja dibuat atau direncanakan untuk mempermudah pelaksanaan pekerjaan yang dikerjakan secara berulang-ulang (PANCA, 2016).

Sedangkan pengetian prosedur menurut Sutabri dalam (Reika Happy Sugiastuti, Moch. Dzulkirom, \& Dwiatmanto, 2014) menyimpulkan bahwa, "Prosedur merupakan urutan kegiatan klerikal. Kegiatan klerikal dilakukan untuk mencatat informasi dalam formulir, buku jurnal, dan buku besar, kegiatan tersebut terdiri dari kegiatan menulis, menggandakan, menghitung, memberi kode, mendaftar, memilih, memindahkan, dan membandingkan.”

\section{Tenaga Kerja}

Menurut Suparmoko dan Icuk Ranggabawonodalam(BITAR, 2019)menyatakan bahwa tenaga kerja ialah penduduk yang sudah memasuki usia kerja dan mempunyai pekerjaan, yang sedang mencari pekerjaan, dan yang melakukan suatu kegiatan lain seperti sekolah, kuliah dan mengurus rumah tangga.

Calon Tenaga Kerja Indonesia yang selanjutnya disebut calon TKI adalah setiap warga negara Indonesia yang memenuhi syarat sebagai pencari kerja yang akan bekerja di luar negeri dan terdaftar di instansi pemerintah kabupaten/kota yang bertanggung jawab di bidang ketenagakerjaan.(S. Rahardjo, 2017)

Perlindungan TKI adalah segala upaya untuk melindungi kepentingan calon TKI dalam mewujudkan terjaminnya pemenuhan hak-haknya sesuai dengan peraturan perundang-undangan, baik sebelum, selama, maupun sesudah bekerja.(S. Rahardjo, 2017)

\section{METODE PENELITIAN}

Tujuan utama dari penelitian adalah mendapatkan data. Teknik pengumpulan data adalah langkah yang strategis dalam sebuah penelitian. Teknik pengumpulan data yang digunakan ABHINAYA selaku penulis dalam mencari beberapa informasi berasal dari berbagai sumber yang berkaitan dengan penelitian, berbagai sumber tersebut sebagai berikut:

a. Observasi; Menurut Nawawi dan Martini (Edra, 2017) Observasi ialah kegiatan mengamati, yang diikuti dengan pencatatan yang berurut, terdiri dari beberapa unsur yang muncul dalam beberapa fenomena yang terjadi didalam objek yang sedang diteliti. Hasil dari proses tersebut kemudian dilaporkan didalam laporan yang sistematis sesuai dengan kaidah yang berlaku.

b. Wawancara; Wawancara merupakan pertemuan dua orang untuk bertukar informasi dan ide melalui tanya jawab, sehingga dapat dikontruksikan makna dalam suatu topik tertentu. Esterberg dalam Sugiyono(Sugiyono, 2014). Penulis menggunakan metode wawancara untuk mendapatkan informasi secara lebih jelas.

c. Kepustakaan; Cooper dalam Creswell mengemukakan bahwa kajian pustaka memiliki beberapa tujuan yakni; menginformasikan kepada pembaca hasil-hasil penelitian lain yang berkaitan erat dengan penelitian yang dilakukan 
saat itu, menghubungkan penelitian dengan literatur-literatur yang ada, dan mengisi celahcelah dalam penelitian-penelitian sebelumnya. (Huda, 2017). Penulis menggunakan metode studi pustaka dengan cara pengumpulan data dengan menggunakan teori-teori dan buku-buku dari beberapa tokoh.

d. Dokumentasi; Menurut Encyclopedia Britanica, pengertian dokumentasi adalah semacam pengawasan dan penyusunan bibliografi yang menggunakan alat-alat seperti indeks, sari karangan dan isi bibiliografi disamping memakai cara tradisioanl "klasik dan katalogisasi", untuk membuat informasi itu dapat dicapai.(Manis, 2017). Penulis mengumpulkan data dokumentasi-dokumentasi saat melakukan penelitian dan perencangan media publikasi.

\section{Metode Analisa Data}

Ada beberapa pengertian tentang metode penelitian, diantaranya :

1. Penelitian Deskriptif; Penelitian deskriptif adalah penelitian yang bertujuan mengumpulkan data atau informasi mengenai suatu gejala atau kejadian yang ada pada saat melakukan penelitian. Penelitian deskriptif bukan bertujuan untuk menguji suatu hipotesis tetapi menggambarkan apa adanya tentang suatu keadaan, variable atau keadaan. (Cut Medika Zellatifanny dan Bambang Mudjiyanto, 2018)

2. Penelitian Kualitatif; Menurut Denzin \& Licoln dalam Albi Anggito dan Johan Setiawan, S.Pd. (Albi Anggito \& Johan Setiawan, 2018) menyatakan bahwa peneliatian kualitatif adalah penelitian yang menggunakan latar belakang alamiah dengan tujuan menafsirkan fonomena yang dilakukan dan terjadi dengan cara melibatkan berbagai metode yang ada.

\section{HASIL DAN PEMBAHASAN}

Setelah melalukan wawancara dan observasi, penulis menggunakan kampanye sebagai alat penyampaian informasinya yang di dukung dengan media-media publikasi yang telah disesuaikan dengan target khalayak dan kebutuhan informasinya.

Dalam perancangan pembuatan desain spanduk, poster dan X Banner, kami memperhatikan dari beberapa unsur, yang diantaranya warna, warna yang kami ambil sebagai dasar dalam desain spanduk, poster dan $X$ Banner ini adalah hijau dan oranye, hijau dan oranyesebagai gambaran dari identitas perusahaan/ logo perusahaan. Dalam desain yang kami buat ada sebuah ilustrasi gambar dua orang perempuan yang kami gambarkan sebagai calon pekerja/ TKW yang ingin proses bekerja keluar negeri, salah satu dari mereka tergiur dengan tawaran calo untuk proses secara non prosedural tetapi salah satu dari wanita tersebut berusaha mengingatkan temannya untuk tidak proses bersama calo tersebut karena PMI Cerdas Stop Ilegalitas.

Elemen desain yang terdapat pada desain kami adalah teks dan gambar. Dalam segi tipografi, desain spanduk, poster dan x-banner kami menggunakan huruf Kollektif dan Arvo yang memiliki karakter regular, bold (tebal) dan memiliki berbagai ukuran agar tidak terlihat monoton.

Dalam kampanye ini kami mengambil judul "PMI Cerdas Stop Ilegalitas" alasan kami mengambil judul ini sebagai tema kampanye kami karena menurut informasi yang kami dapatkan melalui wawancara langsung dengan direktur utama PT Indotama Karya Gemilang dan Tenaga Kerja Indonesia yang sedang bekerja di Hong Kong bahwa yang menjadi permasalahan terbesar dalam perekruitan tenaga kerja Indonesia adalah proses secara legal/ resmi. Banyakanya calon tenaga kerja yang tergiur oleh ajakan calo-calo nakal untuk proses secara ilegal. Karena itu kami mengambil judul ini untuk membantu para calon tenaga kerja untuk memahami pentingnya proses secara legal/resmi.

\section{a. Media Kampanye Spanduk}

Media kampanye spanduk yang kami gunakan berukuran $180 \mathrm{~cm}$ x $80 \mathrm{~cm}$, yang berisi pesan kampanye dipasang di area depan PT QAFCO Beji, Depok, digunakan sebagai pemberitahuan penting mengenai pesan kampanye "TKI Resmi Stop Ilegalitas" pada saat pelaksanaan kampanye yang ingin kami sampaikan.

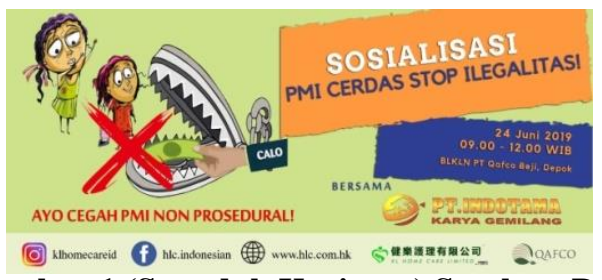

\section{Gambar 1 (Spanduk Kegiatan) Sumber: Desain Pribadi}

\section{b. Media Kampanye Poster}

Media kampanye poster kami menggunakan ukuran 40 x $60 \mathrm{~cm}$ yang berisi pesan kampanye dan akun media sosial dipasang di mading BLKLN PT QAFCO Beji Depok, sebagai media publikasi penting mengenai pesan kampanye "PMI Cerdas Stop Ilegalitas" sebelum dan sesudah acara berlangsung, agar target khalayak mengetahui pesan yang akan disampaikan.

\section{Gambar 2}

(Poster Kegiatan). Sumber: Desain Pribadi

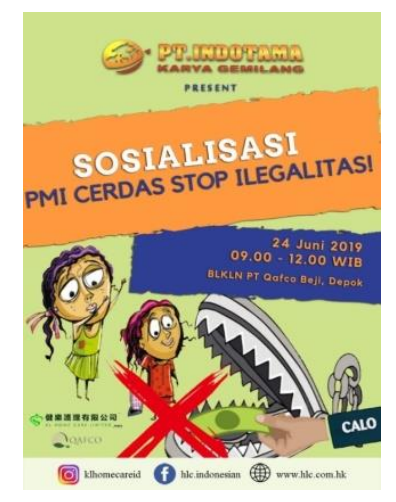




\section{c. Media Kampanye $X$ Banner}

Media kampanye $X$ Banner kami menggunakan ukuran $160 \times 60 \mathrm{~cm}$ yang berisi pesan media sosial diletakan didepan disaat kampanye berlangsung agar peserta sosialisasi mengetahui kampanye yang akan disampaikan "PMI Cerdas Stop Ilegalitas" sebagai media pemberitahuan efektif.

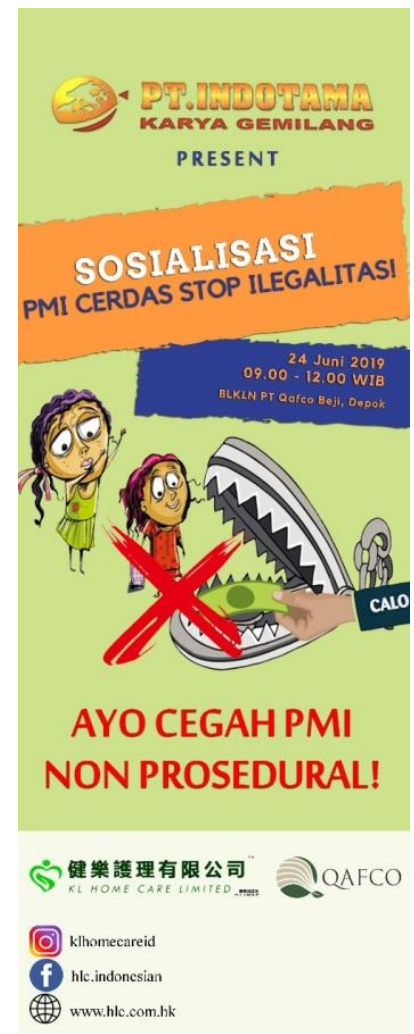

Gambar 3 (X Banner Kegiatan) Sumber : Desain Pribadi

\section{d. Eksekusi Kegiatan Pendukung}

Dalam memaksimalkan media sosial untuk kegiatan kampanye kami, kami memiliki gambaran mengenai tampilan media sosial facebook dan instagram perusahaan. Berikut tampilan media publikasi yang akan kami gunakan dalam pelaksanaan kampanye.

\section{Tampilan Halaman Facebook}

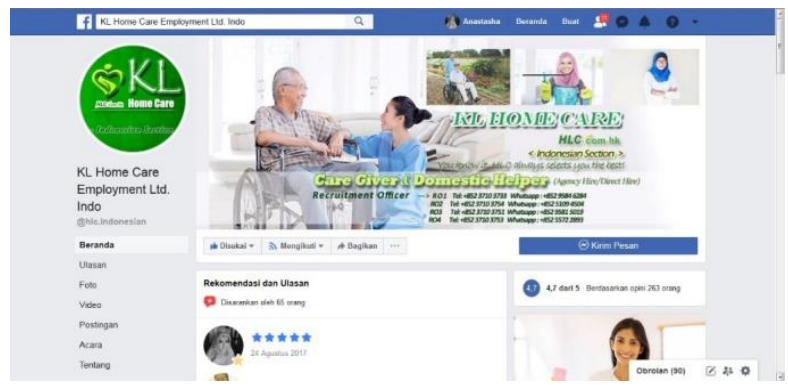

Gambar 4 (Halaman Facebook K1 Home Care Ltd)

\section{Tampilan Halaman Instagram}

() | Instagram

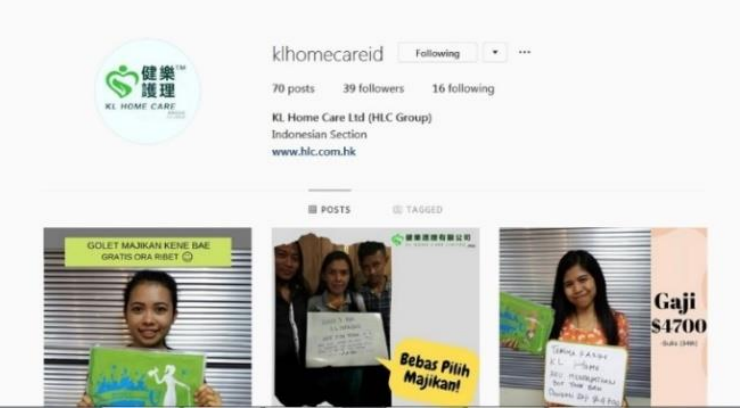

Gambar 5. (Halaman Instagram Kl Home Care Ltd)

\section{Naskah-Naskah Media}

Dalam perencanaan kampanye public relations ini kami menggunakan beberapa media dalam media publikasi, selain poster, $x$ banner dan spanduk kami juga menggunakan media sosial sebagai media publikasi kami, salah satu media yang kami gunakan ialah facebook dan instragram. Dalam publikasi tersebut kami menyiapkan naskah-naskah yang akan digunakan dalam mempublikasikan kampanye kami dalam sosial media, diantaranya :

KL HOME CARE Ltd mengajak sista semua untuk hadir dalam sosialisasi pemberantasan proses ilegalitas yang bertema "PMI Cerdas Stop Ilegalitas" yang akan dilaksanakan pada hari Senin, 24 Juni 2019 pukul 09.00-12.00 WIB. Acara ini akan di selenggarakan di BLKLN PT Qafco Beji, Depok. Ayo daftarkan diri dan jadilah salah satu PMI cerdas yang menolak tegas proses ilegalitas! Untuk informasi lebih lengkap sista bisa hubungi staf Indonesia kami melalui whatsapp berikut +6281310982619 atau klik link https://wa.me/6281310982619. Ayo cegah PMI non prosedural!

\section{KESIMPULAN}

Tenaga Kerja Indonesia (disingkat TKI) adalah sebutan bagi warga negara Indonesia yang bekerja di luar negeri (seperti Malaysia, Timur Tengah, Taiwan, Australia) dalam hubungan kerja untuk jangka waktu tertentu dengan menerima upah. Namun, istilah TKI seringkali dikonotasikan dengan pekerja kasar karena TKI sejatinya memang adalah kumpulan tenaga kerja unskilled yang merupakan program pemerintah untuk menekan angka pengangguran. TKI perempuan seringkali disebut Tenaga Kerja Wanita (TKW). TKI sering disebut sebagai pahlawan devisa karena dalam setahun bisa menghasilkan devisa 60 triliun rupiah (2006), tetapi dalam kenyataannya, TKI menjadi ajang pungli bagi para pejabat dan agen terkait.

Pungli didalam proses perekrutan TKI kerap terjadi di dalam proses non prosedural / ilegal, yang seakan menjanjikan calon TKI bisa bekerja diluar negeri secara cepat tanpa mengikuti proses yang 
sudah diatur oleh pemerintah. Tanpa disadari, proses perekrutan tanpa proses prosedural justru akan menjadi boomerang ketika timbul suatu masalah. Perlindungan hukum yang seharusnya memayungi para TKI tidak akan di dapatkan apabila TKI tersebut masuk secara ilegal. Hal ini membuat kasus-kasus TKI di luar negeri mengalami peningkatan.

Dalam hal ini, sebenarnya pemerintah Indonesia sudah menggandeng beberapa instansi resmi penyalur TKI yang ingin bekerja diluar negeri. Mereka yang melewati proses prosedural / legal akan diberikan pembelajaran, arahan, serta payung hukum yang melindungi TKI ketika mereka bekerja di luar negeri. Alangkah baiknya jika semua calon TKI mengikuti proses secara legal demi kesejahteraan pribadi serta tetap menjadi pahlawan devisa yang baik bagi Indonesia

\section{DAFTAR PUSTAKA}

2, D. P. (2019). Kampanye : Pengertian Menurut Para Ahli, Fungsi, Tujuan, Bentuk, Jenis Dan Medianya. Retrieved May 19, 2019, from dosenpendidikan.com website: https://www.dosenpendidikan.com/pengertian -kampanye-menurut-para-ahli/\#!

Albi Anggito \& Johan Setiawan, S. P. (2018). METODOLOGI PENELITIAN KUALITATIF (E. D. Lestari, Ed.). sukabumi: CV Jejak.

BITAR. (2019). Tenaga Kerja: 13 Pengertian Menurut Para Ahli, Dan Jenis-Jenisnya Beserta Contohnya Secara Lengkap. Retrieved May 19, 2019, from gurupendidikan.com website:

https://www.gurupendidikan.co.id/tenagakerja-13-pengertian-menurut-para-ahli-danjenis-jenisnya-beserta-contohnya-secaralengkap/\#!

Cut Medika Zellatifanny dan Bambang Mudjiyanto. (2018). TIPE PENELITIAN DESKRIPSI DALAM ILMU KOMUNIKASI. Jurnal Diakom, 1(Desember 2018), 83-90. Retrieved from

https://jurnaldiakom.kominfo.go.id/index.php/ mediakom/article/view/20/14

Davie, A. A. (2017). Apa yang dimaksud dengan Kampanye atau campaign?

Derina Holtzhausen, A. Z. (Ed.). (2014). The Routledge Handbook of Strategic Communication.

Dr.Khumaidi. (2015). Paradigma Sains Integratif Alfarabi (Pertama). JAKARTA: Sadra Press.

Dra. Fullchis Nurtjahjani, MM \& Shinta Maharani Trivena, S. (2018). PUBLIC RELATIONS CITRA \& PRAKTEK (F. NURIANSYAH, Ed.). Retrieved from https://books.google.co.id/books?id=EDNyD wAAQBAJ\&printsec $=$ frontcover \&dq $=$ fungsi + dan+tugas+public+relations $\&$ hl=id $\&$ sa $=X \&$ ved=0ahUKEwj26vaD4KXiAhWFdn0KHXs
UBOAQ6AEIMjAC\#v=onepage\&q=fungsi dan tugas public relations $\& \mathrm{f}=$ false

Dra. Fullchis Nurtjahjani, M. \&, \& Shinta Maharani Trivena, SAB., M. (2018). Public Relation, Citra dan Praktek (1st ed.). Malang: POLINEMA PRESS.

Edra, R. (2017). 10 Pengertian Observasi Menurut Para Ahli. Retrieved April 6, 2019, from ruangguru.com website: https://blog.ruangguru.com/10-pengertianobservasi-menurut-para-ahli

Firnandus. (2018). Pengertian Desain Menurut Para Ahli. Retrieved June 23, 2019, from https://www.firnandus.com/ website: https://www.firnandus.com/pengertian-desainmenurut-para-ahli/

FSP, I. (2015). Peran dan Fungsi Public Relation. Retrieved May 19, 2019, from irmanfsp.com website:

http://www.irmanfsp.com/2015/08/peren-danfungsi-public-relation.html

Huda, F. A. (2017). Pengertian dan Definisi Kajian Pustaka. Retrieved May 19, 2019, from fatkhan.web.id website: http://fatkhan.web.id/pengertian-dan-definisikajian-pustaka/

Inoue, T. (2018). Public Relations in Hyperglobalization. London.

KIMBAL, R. W. (2015). MODAL SOSIAL DAN EKONOMI INDUSTRI KECIL SEBUAH STUDI KUALITATIF. YOGYAKARTA: DEEPUBLISH.

Manis, S. (2017). Pengertian Dokumentasi, Fungsi, Tujuan, Peranan dan Kegiatan Dokumentasi Menurut Para Ahli Terlengkap. Retrieved May 19, 2019, from pelajaran.co.id website: https://www.pelajaran.id/2017/28/pengertiandokumentasi-menurut-para-ahli-fungsi-tujuanperanan-kegiatan-dokumentasi.html

Mokhammad. (2018). Jenis-Jenis Media Pembelajaran Menurut Para Ahli dan Contohnya. Retrieved May 19, 2019, from haruspintar.com website: https://www.haruspintar.com/jenis-jenismedia-pembelajaran/

Nasution, A. D. (2017). LOGO SEBAGAI TANDA: ANALISIS MAKNA BENTUK DAN PERANAN WARNA PADA HASIL.

Nurisma, R. A. (2015). Definisi Perancangan Sistem Informasi Akuntansi Persediaan Barang Dagang Menurut Beberapa Ahli. Retrieved May 19, 2019, from kompasiana.com website: https://www.kompasiana.com/rizaadinurisma/ 563d898e9597736e07a63fdd/definisi-

perancangan-sistem-informasi-akuntansipersediaan-barang-dagang-menurut-beberapaahli?page $=$ all

PANCA, A. (2016). Arti Prosedur Menurut KBBI dan Pandangan Ahli. Retrieved from any.web.id website: https://any.web.id/arti- 
prosedur-menurut-kbbi-dan-pandanganahli.info

PENGAREP, H. (2016). PUBLIC RELATIONS YANG KREDIBEL (T. P., Ed.). Retrieved from

https://books.google.co.id/books?id=J6R-

DwAAQBAJ\&printsec $=$ frontcover $\& \mathrm{dq}=\mathrm{TUG}$ AS+PUBLIC+RELATIONS\&hl $=\mathrm{id} \& \mathrm{sa}=\mathrm{X} \& \mathrm{v}$ ed=0ahUKEwjDm8Sm5aXiAhWW4nMBHfz UCiYQ6AEISjAH\#v=onepage $\& q=T U G A S$ PUBLIC RELATIONS\& $\mathrm{f}=$ false

Putera, A. D. (2018). Ini Data TKA di Indonesia dan Perbandingan dengan TKI di Luar Negeri. Retrieved from kompas.com website: https://ekonomi.kompas.com/read/2018/04/23 /154732226/ini-data-tka-di-indonesia-danperbandingan-dengan-tki-di-luar-negeri

Rahardjo, S. (2017). Himpunan Peraturan Perundang-undangan Republik Indonesia Tentang Ketenagakerjaan (Pertama; S. Rahardjo, Ed.). JAKARTA: Penerbit Buana Ilmu Populer.

Rahardjo, S. T., \& Hayuningsih, L. W. (2019). Tinjauan Tiga Desain Kaus Khas Tegal. ANDHARUPA: Jurnal Desain Komunikasi Visual \& Multimedia, 4(01), 25-41. https://doi.org/10.33633/andharupa.v4i01.160 9

Reika Happy Sugiastuti, Moch. Dzulkirom, \& Dwiatmanto. (2014). Jurnal Administrasi Bisnis (JAB)|Vol. 13 No. 1 Agustus 2014|administrasibisnis.studentjournal.ub.ac.i d 1ANALISIS SISTEM DAN PROSEDUR PEMBAYARAN KLAIM KECELAKAAN DALAM UPAYA MENINGKATKAN PENGENDALIAN INTERN (Studi Kasus pada PT.Jasa Raharja(Persero) Kantor. Jurnal Administrasi Bisnis (JAB), 13(1 august 2014), 2. Retrieved from http://administrasibisnis.studentjournal.ub.ac.i d/index.php/jab/article/viewFile/529/728

Satrianawati. (2018). MEDIA DAN SUMBER BELAJAR (PERTAMA). DEEPUBLISH.

Sholikhah, O. H., \& Pradana, L. N. (2018). Geometri Untuk Pendidikan Dasar (Pertama; Darmadi, Ed.). Retrieved from https://books.google.co.id/books?id=5nWDwAAQBAJ\&pg=PA2\&dq=definisi+titik $\& h l=i d \& s a=X \& v e d=0$ ahUKEwi8-
8yb44jjAhWEX80KHW3jDgIQ6AEINjAC\#v $=$ onepage $\& \mathrm{q}=$ definisi titik $\& \mathrm{f}=$ false

Sugiyono. (2014). PERSPEKTIF METODE PENELITIAN KUANTITATIF DAN KUALITATIF. In Metodelogi Penelitian kuantitatif dan kualitatif.

USMAN, A. (2015). JURNAL TUGAS AKHIR UNIVERSITAS TELKOM. E-Proceeding of Art \& Design, 2(DESEMBER 2015), 1013. Retrieved from https://www.google.com/url?sa=t\&rct=j\&q=\& esrc $=$ s\&source $=$ web $\& c d=67 \& c a d=r j a \& u a c t=$ 8\&ved=2ahUKEwiB1r6Z86XiAhXR7nMBH SBwBkc4PBAWMAZ6BAgHEAI\&url=https $\% 3 \mathrm{~A} \% 2 \mathrm{~F} \% 2$ Fopenlibrary.telkomuniversity.ac .id\%2Fpustaka\%2Ffiles\%2F104038\%2Fjurna 1_eproc\%2Fperancangan-kampanye-meng

\section{PROFIL PENULIS}

Silvina Mayasari, S.Sos, M.Si lahir di Padang, 12 Maret 1981 adalah seorang Dosen Program Studi Hubungan Masyarakat di Fakultas Komunikasi dan Bahasa Universitas Bina Sarana Informatika (UBSI). Memulai karirnya di Universitas BSI sejak September 2009. Menyelesaikan Pendidikan S1 di Jurusan Jurnalistik Fakultas Komunikasi Institut Ilmu Sosial dan Ilmu Politik (IISIP) Jakarta pada tahun 2003, dan menyelesaikan Pendidikan S2 Magister Ilmu Komunikasi di Sekolah Pascasarjana Universitas Sahid pada tahun 2016. Penulis saat ini juga tergabung dalam Ikatan Sarjana Komunikasi Indonesia (ISKI).

Mareta Puri rahastine S.Sn, M.I.Kom lahir di Jakarta, 15 Maret 1988 adalah seorang dosen Program Studi Hubungan Masyarakat di Fakultas Komunikasi dan Bahasa Universitas Bina Sarana Informatika (UBSI) sejak Maret 2012. Menyelesaikan S1 di Universitas Pasundan Bandung Jurusan Design Komunikasi Visual (DKV) pada tahun 2011. Dan Selesai S2 di Universitas Mercubuana Jurusan Komunikasi konsentrasi Corporate And Marketing Communication pada tahun 2015.

Natasha Sasmita adalah mahasiswa Fakultas Komunikasi dan Bahasa Program Studi Hubungan Masyarakat Universitas BSI Jakarta. Lahir di Jakarta, 12 September 1997. Penulis giat dalam melakukan pendidikan akademik dan melakukan penelitian. 